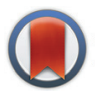

CrossMark

\&lick for updates

Cite this: Org. Chem. Front., 2016, 3 281

DOI: $10.1039 / c 6 q 090004 f$

rsc.li/frontiers-organic

\section{Correction: Palladium-catalyzed oxidative annulation of in situ generated enones to pyrroles: a concise route to functionalized indoles}

\author{
Tenglong Guo, ${ }^{a}$ Quanbin Jiang ${ }^{a}$ and Zhengkun Yu*a,b
}

Correction for 'Palladium-catalyzed oxidative annulation of in situ generated enones to pyrroles: a concise route to functionalized indoles' by Tenglong Guo et al., Org. Chem. Front., 2015, 2, 1361-1365.

The authors regret an error in assigning the funding numbers for this paper. The Acknowledgements section should read, "This work was financially supported by the National Natural Science Foundation of China (21272232) and the National Basic Research Program of China (2015CB856600)".

The Royal Society of Chemistry apologises for these errors and any consequent inconvenience to authors and readers.

${ }^{a}$ Dalian Institute of Chemical Physics, Chinese Academy of Sciences, 457 Zhongshan Road, Dalian, Liaoning 116023, P. R. China. E-mail: zkyu@dicp.ac.cn; Fax: +86-411-8437-9227

${ }^{b}$ State Key Laboratory of Organometallic Chemistry, Shanghai Institute of Organic Chemistry, Chinese Academy of Sciences, 354 Fenglin Road, Shanghai 200032, P. R. China 